\title{
Compound 5a
}

Qualitative Analysis Report

\begin{tabular}{|c|c|c|c|}
\hline Data Filename & CBP-5-106r.d & Sample Name & CBP-5-106 final \\
\hline Sample Type & Sample & Position & Vial 43 \\
\hline Instrument Name & Instrument 1 & User Name & \\
\hline Acq Method & $\mathrm{ESI}+20-100 \% \_12 \mathrm{~min} \cdot \mathrm{m}$ & Acquired Time & 2/18/2016 2:38:01 PM \\
\hline $\begin{array}{l}\text { IRM Calibration Status } \\
\text { Comment }\end{array}$ & Not Applicable & DA Method & 102315.m \\
\hline
\end{tabular}

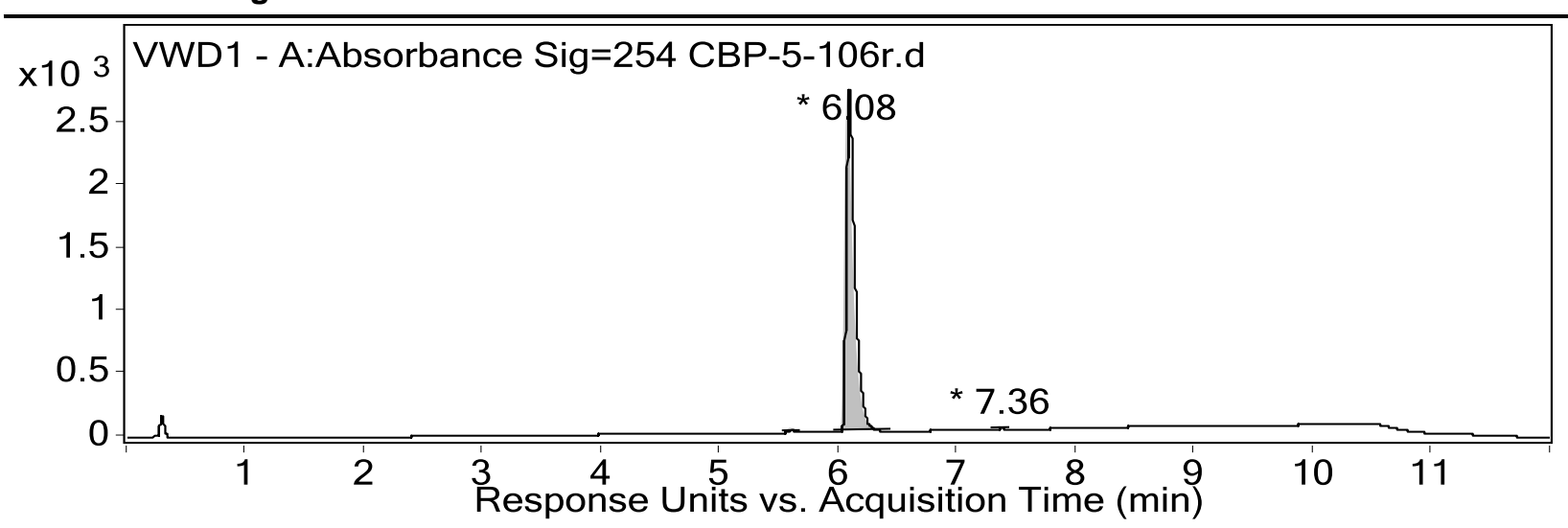

Integration Peak List

\begin{tabular}{|r|r|r|r|r|r|r|}
\hline Peak & \multicolumn{1}{|l|}{ Start } & \multicolumn{1}{l|}{ RT } & \multicolumn{1}{l|}{ lnd } & \multicolumn{1}{l|}{ Height } & \multicolumn{1}{l|}{ Area \% } \\
\hline 1 & 5.53 & 5.6 & 5.68 & 18.98 & 66.92 & 0.49 \\
\hline 2 & 5.96 & 6.08 & 6.45 & 2718.45 & 13654.53 & 100 \\
\hline 3 & 7.29 & 7.36 & 7.45 & 10.28 & 33.68 & 0.25 \\
\hline
\end{tabular}

$\begin{array}{llllll}\text { Fragmentor Voltage } & 165 & \text { Collision Energy } & 0 & \text { Ionization Mode } & \text { ESI }\end{array}$

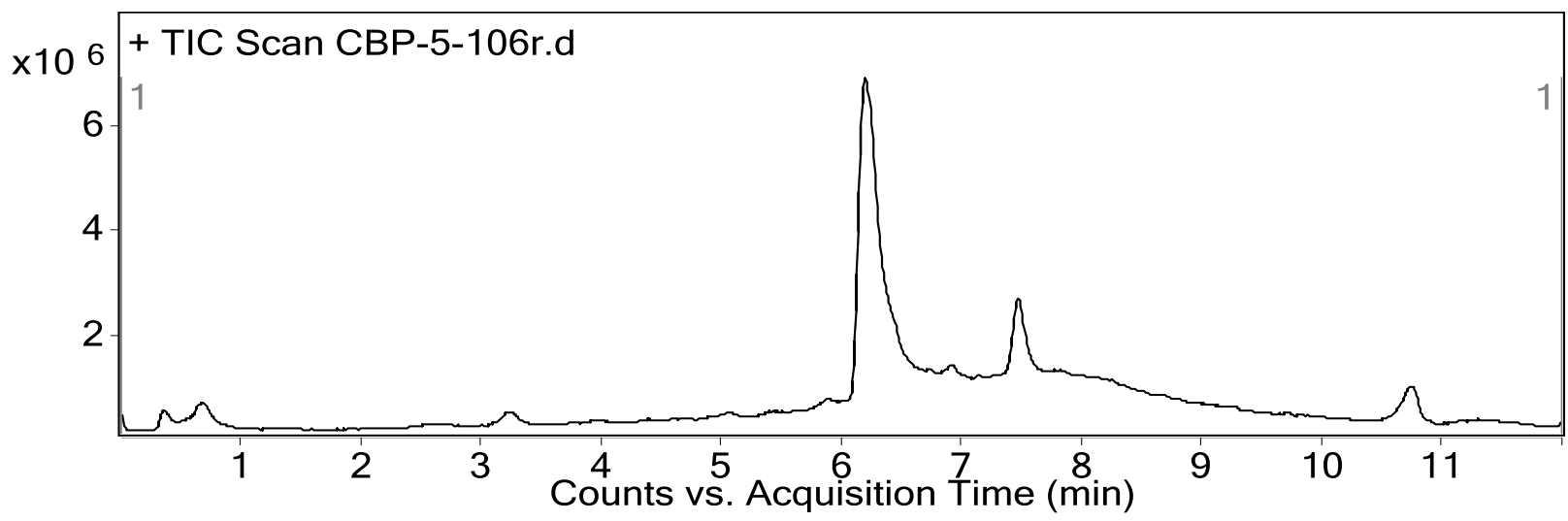

User Spectra

Fragmentor Voltage

Collision Energy

Ionization Mode

165

0

Esi 


\section{Qualitative Analysis Report}

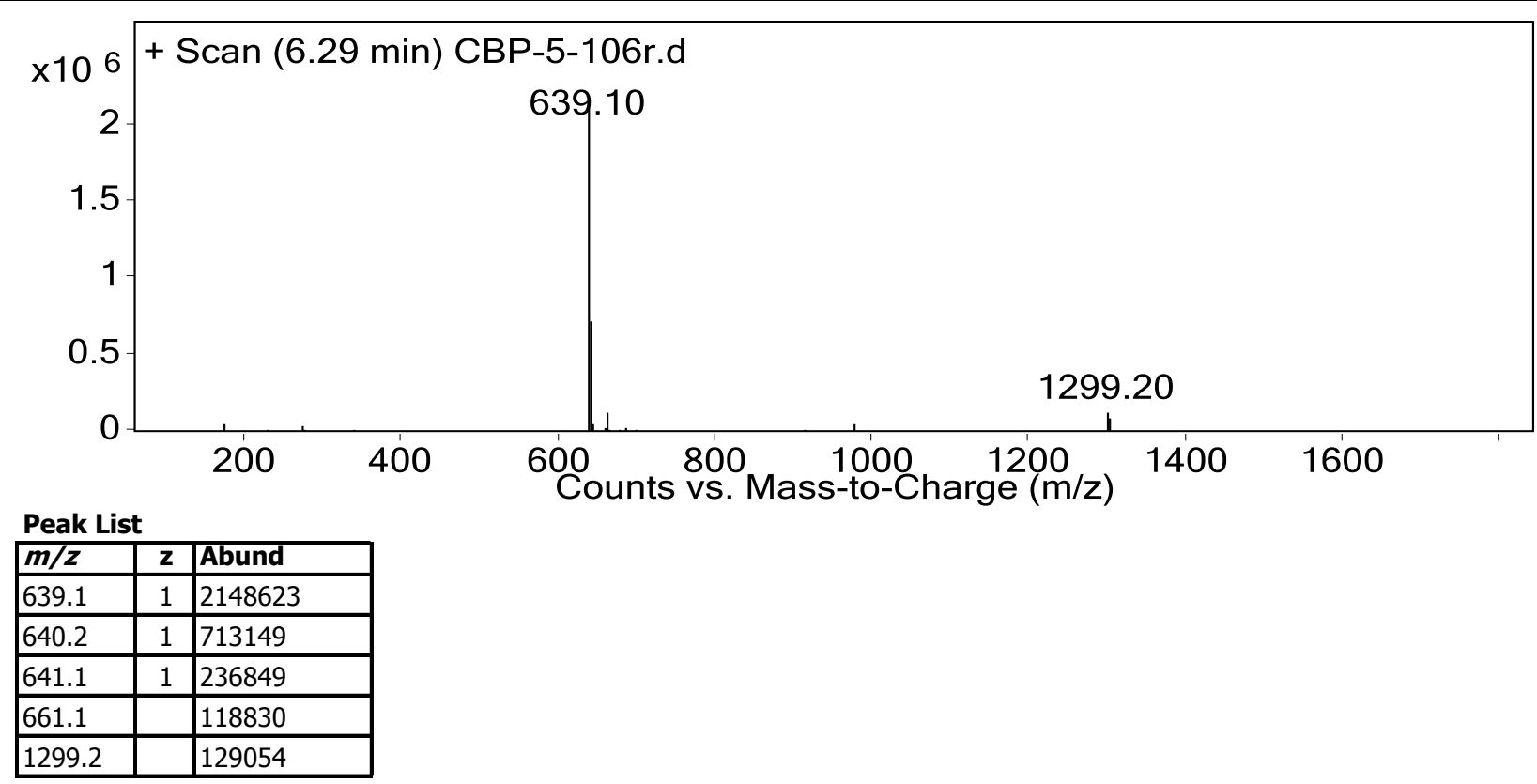

--- End Of Report --- 